\title{
The Economic Impacts of Chronic Illness on Households of Patients in Ile-Ife, South-Western Nigeria
}

Paul T. Okediji ${ }^{1}$, Adedolapo O. Ojo ${ }^{2}$, Akinwumi I. Ojo ${ }^{2}$, Ademola S. Ojo ${ }^{3}$, Opeyemi E. Ojo ${ }^{4}$, Emmanuel A. Abioye-Kuteyi ${ }^{5}$

1. Research \& Development, Sebeccly Cancer Center, Lagos 2. College of Health Sciences, Obafemi Awolowo University, Ile-Ife, Nigeria 3. Department of Surgery, Obafemi Awolowo University, Ile-Ife, Nigeria 4. Department of Medicine, Ekiti State University Teaching Hospital, Ekiti State. Nigeria 5. Department of Family Medicine, Obafemi Awolowo University, Ile-Ife, Nigeria

Corresponding author: Paul T. Okediji, chnovpaul@gmail.com

\section{Abstract}

\section{Introduction}

Chronic illnesses are slowly becoming more prevalent worldwide. The implications and ramifications of these illnesses vary and affect not only the patient but the entire household in many ways. This research focuses on the economic implications of this category of illnesses on the entire household. The aim is to determine the economic implications of chronic illnesses on households of patients in selected health facilities in Ile-Ife, Nigeria, and to elucidate the various coping strategies applied by households in low and middle income countries (LMICs) to keep up with these economic implications.

\section{Methods}

This study features a descriptive cross-sectional survey design with a total sample of 443 . The target population consists of individuals with chronic diseases in selected health care facilities in Ile-Ife.

\section{Results}

The mean household monthly incomes before and after illness episodes were found to be $\$ 335.84$ and $\$ 318.01$, respectively. The mean direct cost of chronic illness was $\$ 137.72$ with about $79 \%(n=350)$ of the respondents spending more than $10 \%$ of the monthly household income on health. The indirect costs of illness were a loss of productivity of $18.9 \%$ and $5.1 \%$ for patients and caregivers, respectively. A large percentage of the respondents resorted to borrowing $(44.7 \%$; $n=198)$, while another $5.0 \%(n=22)$ sold assets, and $8.6 \%(n=38)$ had access to health insurance in order to cope with the economic impacts of the illness.

Received 07/18/2017 Review began 08/01/2017 Review ended 10/05/2017 Published 10/07/2017

(c) Copyright 2017 Okediji et al. This is an open access article distributed under the terms of the Creative Commons Attribution License CC-BY 3.0., which permits unrestricted use, distribution, and reproduction in any medium, provided the original author and source are credited.

\section{Conclusion}

The study showed that chronic illnesses imposed high and catastrophic cost burdens on patients and their households. The lack of effective coping strategies points at the need for policymakers to improve access to specialized care and increase coverage of formal health insurance so as to ameliorate the significant economic impacts that chronic illnesses have on entire households.

Categories: Internal Medicine, Other, Epidemiology/Public Health

Keywords: nigeria, lmic, chronic illness, economic impacts, cost of illness, direct costs, coping, household

\section{Introduction}

Chronic illnesses such as diabetes mellitus, cardiovascular disease, cerebrovascular disease, cancers, chronic respiratory diseases, mental illnesses, and other non-communicable diseases have become major issues globally [1]. Between 1980 and 2015, non-communicable chronic illnesses accounted for 71.3\% (about 40 million) of all deaths [2]. Furthermore, the World Health Organization (WHO) estimated that $80 \%$ of the deaths due to chronic illnesses occurred in low and middle-income countries (LMICs) with developing economies [3]. These chronic and slowly progressive illnesses are becoming increasingly prevalent as a result of significant changes in lifestyle, reduction in death rates, increased longevity, and an improvement in health services in many countries. Attendant implications include a higher medical bill which can lead to economic impoverishment (which is broadly defined as a process of household income and asset depletion which cause consumption levels to fall below minimum needs) and significant morbidity and mortality in low and middle-income countries (LMICs), including Nigeria [4].

Chronic illnesses have been associated with disability and this can have damaging, or serious economic implications on the individual and his/her family as they generally deprive individuals of their productivity and health potentials [5]. From the national perspective, chronic illnesses reduce both work capacity and life 
expectancy, and therefore, economic productivity; leading to a reduction in the quantity and quality of the nation's labor force [6]. Invariably, the burden of chronic illnesses primarily impacts the income and depletes investment savings of the individual and the household. Usually, the direct economic impacts on the household may arise typically in the form of hospital bills, caregiver allowances, nursing home bills, and other aspects of care [5]. For LMICs which place poverty reduction at the center of developmental targets and strategies, the increase in the prevalence of chronic illnesses poses a serious threat to the achievement of these targets.

Different approaches have been employed in studying the economic burden of illnesses such as the cost of illness (COI), microeconomic and macroeconomic approaches [5]. The COI approach is suitable for this study because of its ability to highlight the economic magnitude of a chronic disease and/or its associated risk factors, which accounts for both direct medical and non-medical costs, and indirect losses due to foregone productivity $[5,7]$. It is clear that there are costs associated with being sick - the cost of obtaining treatment for the chronic illness, the cost of travel to access care, the income forgone because of the inability to work or perform normal duties as a result of the illness. These costs have been divided into direct, indirect, and intangible costs [7].

Direct costs estimate the household's spending on medical care as far as the prevention, diagnosis, and treatment of the illness are concerned [5]. These include the costs accrued as a result of the use of medications, hospital admissions, ambulances or other means of transportation to the hospital or point-ofcare, in-patient care or out-patient care (clinics), rehabilitation, and community health services. On the other hand, indirect costs represent the loss of man hours or labor that is caused by morbidity/mortality arising from the disease. The human capital approach of measuring indirect costs looks at the lost labor time due to the illness which often translates to a reduced household capacity to earn income, especially at a time when it needs the additional money to pay for treatment $[8,9]$. There is also the much broader "willingnessto-pay" method of measuring indirect costs, which focuses on the amount of money people are willing to pay for relatively small changes to avert the risk of death [5]. The third category, and most difficult to measure, is the intangible cost, which encompasses the psychological dimensions that people attribute to illness, usually in the form of pain, anxiety, suffering, and bereavement.

The household has been selected in similar studies as the preferred unit of analysis for evaluating illness costs because: (i) major decisions concerning treatment and coping strategies are determined at the household level, (ii) most of the costs of managing an illness are borne by both the sick individual and other members of the household, and (iii) the costs of illness fall on the household budget [8]. The "cost burden" has to do with the proportion of the family income spent on obtaining treatment; and when this goes beyond what the family can easily bear, it triggers the use of coping strategies such as borrowing or selling off of assets. For many Nigerian families, the first point of call for seeking for funds is from social networks (the larger/extended family, friends, social groups), or local organizations that offer credit. Both illness costs and coping strategies have serious implications for household asset portfolios and processes of impoverishment [8]. There is presently a dearth of information on the economic impact of chronic illnesses on households in the Nigerian population. Hence, the primary focus of this study is to assess the effects of chronic illnesses on the expenditure of the household and labor income; and to investigate the influence of health insurance and other sources of funds on the economic shocks of chronic diseases.

\section{Materials And Methods}

A total of 443 patients who were either attending clinics or on admission for various chronic illnesses at the Obafemi Awolowo University Teaching Hospitals' Complex (OAUTHC), and the Seventh-Day Adventist Hospital; both in Ile-Ife, Nigeria, between February and March 2012 were sampled. Patients were consecutively recruited, and included in this research if: (i) they were 18 years and above, (ii) had a definitive diagnosis of at least one chronic illness, and (iii) had been in treatment for their disease for at least three months. The length of time was given for them to have experienced significant costs associated with managing their condition. Patients who were too ill to respond and/or did not give informed consent were excluded from the study.

Data was obtained from the patients with the aid of an interviewer-administered questionnaire adapted from the study by Jeon, et al. [10]. The questionnaire sought information on socio-demographic data, selfreported health status, treatment behavior, economic status, affordability of health care, affordability of other essentials, and coping strategies. Information was also obtained on the patients' current work status, loss of productive labor time due to illness, presence of financial difficulties or financial pressure, actual income lost for each respondent, actual cost of the patient's healthcare per week or per month, effects on the caregiver, and whether the respondents received any government benefits. Questionnaire information was entered into a microcomputer and analyzed with the level of statistical significance set at $<0.05$. Ethical approval was obtained from the Ethics and Research Committee of the OAUTHC, Ile-Ife. All respondents gave informed consent prior to their participation in the study, and the study was conducted in line with the principles of the Helsinki declaration.

\section{Results}




\section{Cureus}

The results obtained were analyzed with the use of the Statistical Package for the Social Sciences [SPSS] (IBM Corp., Armonk, NY) version 16 software. Descriptive and inferential statistics (chi-square analysis and independent $\mathrm{t}$-tests) were performed and the results are presented in tables.

\section{Subjects' characteristics}

A large proportion $(64.8 \% ; n=287)$ of the respondents were between 18 and 64 years (Table 1$)$. There were more females $(52.1 \% ; n=231)$ than males $(47.9 \% ; n=212)$. Concerning employment, $64.6 \%(n=286)$ of the respondents were in a paid employment while the rest were not in any form of paid employment, and this includes those who were retired, unemployed, or not active. Patients were asked about their self-evaluated health status and about $71 \%(n=315)$ said that their health was at least good while $2.9 \%(n=13)$ had a perception of poor health. Hypertension was found to be the most common chronic illness among the population studied (65.2\%; $n=289)$, followed by diabetes $(32.1 \%$; $=142)$. About $37 \%(n=164)$ had illnesses lasting between three and 12 months, 31.8\% ( $\mathrm{n}=141)$ had been ill for 13-60 months, while the remaining $31.2 \%(\mathrm{n}=138)$ had been ill for more than five years. The first place of treatment was the health care facility for about $92 \%(n=407)$ of subjects.

\begin{tabular}{|c|c|c|}
\hline & Frequency $(n=443)$ & Percentage (\%) \\
\hline \multicolumn{3}{|l|}{ Age } \\
\hline 18 - 64 years & 287 & 64.8 \\
\hline 65 years and older & 156 & 35.2 \\
\hline \multicolumn{3}{|l|}{ Gender } \\
\hline Male & 212 & 47.9 \\
\hline Female & 231 & 52.1 \\
\hline \multicolumn{3}{|l|}{ Marital status } \\
\hline With a partner (married/co-habiting) & 341 & 77.0 \\
\hline No partner (single/separated/divorced/widowed) & 102 & 23.0 \\
\hline \multicolumn{3}{|l|}{ Employment status } \\
\hline Paid Employment/self employed & 286 & 64.6 \\
\hline Not in paid employment & 157 & 35.4 \\
\hline Had a Carer & 378 & 85.3 \\
\hline \multicolumn{3}{|l|}{ Type of chronic illness ${ }^{\star}$} \\
\hline Hypertension & 289 & 65.2 \\
\hline Diabetes & 142 & 32.1 \\
\hline Cancer (all types) & 14 & 3.2 \\
\hline Bone or joint problems & 37 & 8.4 \\
\hline Chronic kidney disease & 7 & 1.6 \\
\hline Chronic liver disease & 23 & 5.2 \\
\hline Heart disease & 32 & 7.2 \\
\hline Mental illness & 48 & 10.8 \\
\hline Others & 8 & 1.8 \\
\hline \multicolumn{3}{|l|}{ Duration of illness } \\
\hline <12 months & 164 & 37.0 \\
\hline $13-60$ months & 141 & 31.8 \\
\hline$>60$ months & 138 & 31.2 \\
\hline
\end{tabular}




\section{Cureus}

Place of first treatment before going to the hospital

Pastor

8

1.8

Family members

Chemist

7

1.6

18

4.1

Traditional healer

3

0.7

Healthcare facility

407

91.9

Drug adherence over the last 30 days

148

33.4

Use of alternative treatments like herbal remedies

107

24.2

*Some of the respondents had more than one of the index conditions.

\section{TABLE 1: Socio-demographic, clinical and behavioral characteristics of subjects}

\section{Direct costs of chronic illness to households}

The mean direct cost of chronic illness obtained from the respondents was $\$ 137.72$, constituting $43.3 \%$ of the mean household income (Table 2). The mean monthly household spending on non-health goods and services was $\$ 180.30$. When the direct cost of treatment of the subject's chronic illnesses was expressed as a proportion of the monthly household income, only $21.9 \%$ of the respondents spent less than $10 \%$ of their monthly income on health while more than $40 \%$ of subjects spent over $40 \%$ of monthly income on healthcare (Table 3). A comparison of the means of the household monthly income, before and after the onset of illness, showed no statistical difference $(\mathrm{p}=0.07)$. Medications constituted the bulk of the direct costs, making up $49.7 \%$ of the whole household spending on health. Transportation cost was the least, taking up $6.9 \%$ of the direct costs.

\begin{tabular}{|c|c|c|}
\hline \multirow[b]{2}{*}{ Monthly Income } & \multicolumn{2}{|l|}{$n=443$} \\
\hline & Mean (\$) & SD (\$) \\
\hline Household monthly income before the illness & 335.84 & 602.95 \\
\hline Household monthly income since the illness started & 318.01 & 533.43 \\
\hline Change in monthly income & -17.82 & 208.53 \\
\hline \multicolumn{3}{|l|}{ Direct average monthly costs of chronic illness } \\
\hline Drugs & 68.43 & 177.97 \\
\hline Laboratory investigations & 18.62 & 70.82 \\
\hline Admission & 28.92 & 153.31 \\
\hline Other forms of treatment (rehabilitation, community health services) & 12.94 & 82.68 \\
\hline Transportation to the hospital & 8.81 & 28.47 \\
\hline Total & 137.72 & 359.54 \\
\hline Household monthly non-health expenditure & 180.30 & 647.41 \\
\hline
\end{tabular}

TABLE 2: Household monthly income and direct costs of chronic illness among respondents 


\section{Cureus}

\begin{tabular}{|c|c|c|}
\hline & Frequency $(n=443)$ & Percentage (\%) \\
\hline \multicolumn{3}{|l|}{ Monthly income } \\
\hline$\leq \$ 138$ & 206 & 46.5 \\
\hline$>\$ 138$ & 237 & 53.5 \\
\hline \multicolumn{3}{|c|}{ Direct chronic illness costs } \\
\hline$\leq 10 \%$ & 97 & 21.9 \\
\hline $11 \%-20 \%$ & 76 & 17.1 \\
\hline $21 \%-30 \%$ & 55 & 12.4 \\
\hline $31 \%-40 \%$ & 26 & 5.9 \\
\hline$>40 \%$ & 189 & 42.7 \\
\hline
\end{tabular}

TABLE 3: Household monthly income; and monthly direct health expenditure as a proportion of household monthly income of respondents

\section{Indirect costs of chronic illness to households}

The indirect costs of the chronic illness on both patients and caregivers who were members of the households were estimated using the number of work days lost per month to illnesses and change of jobs during the period of the index illness. As shown in Table 4, on the average, 5.3 work days were lost by patients in a month, constituting about $18.9 \%$ lost productivity while caregivers only lost on average 1.4 work days constituting $5.1 \%$ lost productivity. About $15 \%$ of subjects lost more than $50 \%$ of work days in the preceding month. Also, approximately $12 \%$ of caregivers had to seek other ways to make more money to take care of family needs as a result of the burden of the illness.

\begin{tabular}{|c|c|c|}
\hline \multirow[b]{2}{*}{ Days lost per patient per month } & \multicolumn{2}{|l|}{$n=443$} \\
\hline & Frequency & Percent (\%) \\
\hline$<5$ days & 353 & 79.7 \\
\hline 6-10 days & 10 & 2.3 \\
\hline 11-15 days & 15 & 3.4 \\
\hline$>15$ days & 65 & 14.7 \\
\hline Indirect costs & Mean (days) & SD (days) \\
\hline Patient & 5.30 & 10.37 \\
\hline Caregiver & 1.42 & 5.53 \\
\hline
\end{tabular}

TABLE 4: Indirect costs of illness as days lost within the last 30 days to patients and caregivers SD: standard deviation

\section{Affordability of healthcare}

Considering the impact of the costs of healthcare, $38.6 \%(n=171)$ of the respondents had at least one unsatisfied basic need such as food, shelter, and clothing partly due to the burden of chronic illness (Table 5). A significant proportion of subjects could not afford key elements of care for their condition, as shown in Table 5, while between 35 and $50 \%$ of subjects had difficulties securing basic necessities, maintaining lifestyle and social integration due to the economic burden of their chronic illness. In particular, $35.2 \%$ 


\section{Cureus}

$(n=156)$ of the respondents experienced financial difficulties in the area of economic capabilities. These financial difficulties influenced their treatment choices, as money was the determining factor in $8.8 \%(n=39)$ of treatment choices, although the doctor's prescription (88.5\%; $\mathrm{n}=392)$ and family's decision $(2.7 \% ; \mathrm{n}=12)$ influenced treatment choices significantly. Thus, most respondents made health care their priority need and obtained health care at the expense of other needs.

\begin{tabular}{|c|c|c|}
\hline Description & Frequency & Percentage \\
\hline Ability to finance all medications & 268 & $60.5 \%$ \\
\hline Ability to finance all laboratory investigations & 316 & $71.3 \%$ \\
\hline Ability to finance admission when necessary & 249 & $56.2 \%$ \\
\hline Difficulty purchasing basic necessities since the illness started & 156 & $35.2 \%$ \\
\hline Difficulty in maintaining normal lifestyle since the illness started & 207 & $46.7 \%$ \\
\hline Had to cut back on some things usually bought before the illness & 210 & $47.4 \%$ \\
\hline Had reduced participation in some social and leisure activities due to cost of treatment & 196 & $44.2 \%$ \\
\hline
\end{tabular}

TABLE 5: Affordability of healthcare and other essentials among respondents

\section{Coping strategies among respondents}

It was observed that $44.7 \%(\mathrm{n}=198)$ of the respondents had, at one time or the other, borrowed money in order to meet the costs of treatment (Table 6). Of the lenders, friends constituted the majority (54.5\%; $\mathrm{n}=108)$, followed by family $(19.2 \%$; $\mathrm{n}=38)$, cooperative societies $(18.2 \% ; \mathrm{n}=36)$, church $(4.5 \%$; $\mathrm{n}=9)$, and banks $(3.5 \% ; n=7)$. About $5.0 \%(n=22)$ of the respondents had to sell assets to finance treatment. Of the 443 respondents, only $8.6 \%(n=38)$ had health insurance. Most of the insured respondents $(94.7 \%$; $n=36)$ claimed that the health insurance reduced the impact of the chronic illness on the finances of the household.

\begin{tabular}{|l|l|}
\hline Had borrowed money for any aspect of treatment at any time & Frequency (\%) \\
\hline Source of borrowed money $(\mathrm{n}=198)$ & $198(44.7 \%)$ \\
\hline Bank & $7(3.5 \%)$ \\
\hline Cooperative society & $36(18.2 \%)$ \\
\hline Church & $9(4.5 \%)$ \\
\hline Friends & $108(54.5 \%)$ \\
\hline Family & $38(19.2 \%)$ \\
Sold assets to get money for treatment & $22(5.0 \%)$ \\
\hline Health insurance ownership & $38(8.6 \%)$ \\
\hline Health insurance reduced the impact of the chronic illness on the household & $36(94.7 \%)$ \\
\hline
\end{tabular}

TABLE 6: Coping strategies in use among respondents

The majority of respondents with a single chronic illness spent less than $10 \%$ of their average household monthly income on health, while the majority of those who had multiple chronic illnesses spent more than $10 \%$ ( $\mathrm{p}=0.001$; Table 7 ). There was no statistically significant difference in the number of days lost to illness (indirect costs) between subjects with one chronic illness and those with multiple chronic illnesses ( $p=0.42$; Table 8). However, the indirect costs of illness varied with the type of illness, as cancers resulted in $45.1 \%$ lost productivity as compared with diabetes and hypertension that resulted in about $15 \%$ lost productivity. The monthly health expenditure of those who could satisfy their basic needs was statistically lower than that of those who could not ( $\mathrm{p}=0.02$; Table 8 ). Patients and families who spent less than $10 \%$ of their total 


\section{Cureus}

monthly income on health were more likely to have their basic needs satisfied than those who spent more on health ( $\mathrm{p}=0.001$; Table 7 ).

\begin{tabular}{|c|c|c|c|}
\hline \multirow[b]{2}{*}{ Number of chronic illness } & \multicolumn{2}{|c|}{ Proportion of monthly income spent on health } & \multirow[t]{2}{*}{ Remarks } \\
\hline & $<10 \%$ & $>10 \%$ & \\
\hline Single illness & $87(28.3 \%)$ & $220(71.7 \%)$ & \multirow{2}{*}{$p=0.001^{*}$} \\
\hline Multiple illnesses & $17(12.5 \%)$ & $119(87.5 \%)$ & \\
\hline Unsatisfied basic need & $<10 \%$ & $>10 \%$ & \\
\hline Yes & $16(15.4 \%)$ & $155(45.7 \%)$ & \multirow{2}{*}{$p=0.001^{*}$} \\
\hline No & $88(84.6 \%)$ & $184(54.3 \%)$ & \\
\hline \multicolumn{4}{|l|}{${ }^{*} p$-value is significant $(<0.05)$} \\
\hline
\end{tabular}

TABLE 7: Respondents' characteristics and proportion of monthly income spent on chronic illness 


\section{Cureus}

\begin{tabular}{|c|c|c|c|c|}
\hline & $n=443$ & Mean & SD & p-value \\
\hline Type of illness & & Mean monthly direct costs (\$) & SD (\$) & \\
\hline Cancer & 14 & 489.07 & 499.32 & - \\
\hline Chronic kidney disease & 7 & 299.98 & 323.08 & - \\
\hline Mental illness & 48 & 249.65 & 687.96 & - \\
\hline Bone or joint problem & 37 & 169.22 & 287.23 & - \\
\hline Chronic liver disease & 23 & 162.17 & 318.91 & - \\
\hline Diabetes & 142 & 159.76 & 392.00 & - \\
\hline Hypertension & 289 & 104.89 & 288.94 & - \\
\hline Heart disease & 32 & 76.58 & 81.74 & - \\
\hline Anemia & 1 & 49.92 & - & - \\
\hline Asthma & 6 & 42.33 & 33.87 & - \\
\hline Sickle cell disease & 1 & 31.95 & - & - \\
\hline No of illnesses & & Mean number of days (days) & SD (days) & \\
\hline Single illness & 307 & 5.0 & 10.11 & \\
\hline Multiple illnesses & 136 & 5.9 & 10.94 & \\
\hline Ability to satisfy basic needs & & Mean direct costs (\$) & SD (\$) & \\
\hline Yes & 287 & 108.71 & 238.95 & \\
\hline No & 156 & 191.07 & 508.77 & \\
\hline
\end{tabular}

TABLE 8: Costs of illness by illness type, number of illnesses, and ability to satisfy basic needs SD: standard deviation

\section{Effect of employment on monthly income}

Considering the average household monthly incomes and expenditures before and after the onset of illness by employment status, it is clear that those in paid employment had a higher mean monthly income both before and after the illness than those without a paid employment. However, the differences between the two groups were not statistically significant in both cases (before and after illness; $p>0.05$; Table 9). Also, when the change in monthly income as a result of the illness is considered, it appears that those in paid employment had a lesser change in monthly income, although the difference between the two groups, as seen in Table 9 , was not statistically significant ( $>>0.05$ ). Those who were in paid employment had more money available for spending on other essentials $(\$ 219.99 \pm 687.74)$ than those who did not have a paid employment $(\$ 180.30 \pm 561.51)$. Nonetheless, these averages were comparable between the two groups as the difference between them was not statistically significant $(\mathrm{p}>0.05)$. 


\section{Cureus}

\begin{tabular}{|c|c|c|c|c|c|}
\hline \multirow[t]{2}{*}{ Average monthly income/expenditure } & \multicolumn{2}{|c|}{ Paid employment ( $\mathrm{n=286)}$} & \multicolumn{2}{|c|}{ Unpaid employment ( $n=157)$} & \multirow[b]{2}{*}{$\mathrm{p}$-value } \\
\hline & Mean (\$) & SD (\$) & Mean (\$) & SD (\$) & \\
\hline Household monthly income before the illness & 362.94 & 694.87 & 286.46 & 379.66 & 0.20 \\
\hline Household monthly income since the illness started & 349.82 & 595.46 & 260.06 & 391.40 & 0.09 \\
\hline Change in monthly income & 13.12 & 230.59 & 26.39 & 161.09 & 0.52 \\
\hline Amount available to be spent on other things & 219.99 & 687.74 & 180.30 & 561.51 & 0.08 \\
\hline \multicolumn{6}{|c|}{$\begin{array}{l}\text { IABLE 9: Average nousenoid montniy incomes Detore ana atter IIIness onset oy employment } \\
\text { status }\end{array}$} \\
\hline SD: standard deviation & & & & & \\
\hline
\end{tabular}

\section{Discussion}

In our sample of 443 respondents, approximately $65 \%$ of them were in paid employment while the remaining were either unemployed or retired. Being in a paid employment often implies additional benefits accruing to an employed person for most workers in Nigeria. In a way, a worker receives entitlements in forms of wages, bonuses, paid sick leaves, and sometimes employer-paid healthcare which may cushion the effects of treating any chronic illness within the household. First, those who were in paid employment experienced a lesser change in monthly income as a result of the disease (\$13.12), as against those who were not in paid employment who experienced a relatively larger change in monthly income of $\$ 26.39(p>0.05)$. Secondly, those who had paid employment had a higher average monthly income $(\$ 362.94)$ relative to those who were not in paid employment (\$286.46), which suggests that employed individuals have additional funds to cater for the costs of illness, and a relatively reduced burden of chronic disease on the family. Also, those who were in a paid employment had more money to spend on other essential things (\$219.99) as against $\$ 180.30$ for those who were not in a paid employment (Table 9 ). This difference between the two groups was not significant ( $>0.05$ ), but suggests that being in a paid employment can somewhat cushion the effects of chronic illnesses on households. However, in many developing countries where unemployment rates are very high and paid employment is not readily available to cushion the costs of chronic illnesses on families, the effects can be very devastating.

While not all the respondents had to pay for admission or other specific forms of treatment as the requirements of managing each disease varied, almost all had to pay for drugs and investigations. It is expected that laboratory investigations and drugs are essential parts of any disease management which should be common to all the chronic illnesses studied [5]. However, the disease-specific needs may have accounted for the wide differences in the mean direct cost for each treatment parameter as some respondents, for instance, went through hospital admissions while others did not. Of the treatment parameters, drugs constituted the largest proportion of the direct costs to the respondents. It has been explained that direct costs include medical and non-medical costs but the proportions spent on these may be varied due to supply factors such as availability, accessibility, and user fee policy [8]. Some respondents may have to travel long distances because of the unavailability of specialist care. Particularly in Nigeria, as well as many other LMICs where chronic illnesses are mostly managed in tertiary healthcare faculties which are, largely few and mostly owned by the government; the cost of transportation becomes very significant. This forces many of the respondents to pay more for transport and, therefore, makes non-medical costs a larger proportion of direct costs for such subjects (as reflected in the data spread and huge standard deviations). It is also a reflection of the accessibility to needed care, implying that specialized services to manage chronic illnesses are not freely available, especially when patients have to travel far to access care.

The average household monthly incomes before and after illness onset were found to be $\$ 335.84$ and $\$ 318.01$ respectively, showing a mean drop of $\$ 17.82$. This unexpectedly small mean change in monthly income despite the fact that some subjects were not able to work at all, or had an increased absenteeism from work, could have been due to the time frame as the duration of illness was as long as 30 years in some subjects. As a result of this, using the resulting change in monthly income as one of the economic effects of chronic illness is flawed $[5,11]$. However, other studies have found a statistically significant fall in expected earnings as a result of chronic illness within five to six years [12].

With a mean direct cost of $\$ 137.72$ and an average household monthly income of $\$ 318.01$, the average proportion of the household income spent on health was $43.3 \%$. It has been shown that a direct cost burden of illness greater than $10 \%$ is catastrophic [8, 13-15] even though some studies have used $40 \%$ as the benchmark for catastrophic health spending [16]. This means the average household should not spend more than $\$ 31.80$ (10\%) in order not to experience significant financial stresses. However, the majority of the 
households spent far beyond that. In this study, only $21.9 \%$ of the respondents spent less than $10 \%$ of their monthly income while about $43 \%$ spent more than $40 \%$ of monthly income on their illness. Unlike studies reporting that the majority of households incurred a low burden of direct illness costs because of access to free public healthcare for the regular treatment of chronic illnesses and inpatient care, this study reflects the deficiency of such protective measures $[17,18]$. A large direct cost burden may also reflect the relatively low household income, as direct cost burden has an inverse relationship with the household income [9]. As seen in this study (Table 3), about $46 \%$ of the households earned less than the mean direct cost of treating their illness (\$137.72).

One way to determine the indirect cost of illness is to use the lost labor time due to the illness which translates to a reduced household capacity to earn income (especially at a time when it needs additional money to pay for treatment) [8]. The indirect costs of illness for both the patients and caregivers are 5.30 and 1.42 days respectively, implying that caregivers devoted an average of two days in a month to take care of their sick relatives. This is a widely used indicator of the effect of illness on the labor supply [5]. Converting these figures to a monetary value using the gross domestic product (GDP) per capita of Nigeria of $\$ 2,436$ (at the time of study), the mean loss per subject was $\$ 503.92$, annually, which is equivalent to 1.5 months' average income as found in the study, while the caregiver lost an average of $\$ 134.56$ annually- equivalent to approximately $50 \%$ of the average monthly wage [19-20]. This shows a significant economic impact even though this indicator fails to capture other indirect costs, including intangible costs that are difficult to estimate. Nonetheless, the huge loss of productivity and income can have significant implications on a country's economic status, particularly if the prevalence of chronic illnesses continues to rise in LMICs as recent estimates have shown [2-3].

In response to chronic illness, the most common coping strategies used included borrowing (44.7\%), health insurance (8.6\%), and selling off of assets (5.0\%). For those that borrowed money, the major sources were friends and families (together amounting to 73.7\%). Russell [4] explains that friends and families constitute the most important source of social support, and this has been buttressed by these results. Other sources were from the bank, cooperative societies, and churches. Obtaining bank loans for use on health is difficult in the study environment. However, cooperative societies have taken the place of banks for a lot of people, making it easier to save and also obtain overdrafts when the need arises without having to provide significant collaterals. The fact that $44.7 \%$ of the respondents borrowed money in this study is in contrast to a Thai study which showed that only $15 \%$ borrowed money [21]. This may have been due to the low coverage of health insurance found in this study (8.6\%) in contrast to $76 \%$ in Thailand [22]. This contrast between Nigeria and Thailand also points at the need for Nigeria, as well as other LMICs, to improve the penetration of and accessibility to health insurance. Many developed nations have well-established national health insurance systems which guarantee healthcare based on clinical need at affordable levies/premiums [18]. Total out of pocket cost of all illnesses in such environments is usually much less than $10 \%$ of the monthly household income at the point of care for most people [8]. This goes a long way in protecting the average household from the catastrophic and devastating effects that the treatment of a patient's chronic illness has.

About $85 \%$ of the respondents had caregivers, a finding that reflects the influence of social networks on the economic burden of chronic illness on households in our environment. According to Russell [4], social networks are important in the provision of viable coping strategies, the most vital component of this network being the immediate family. Therefore, the presence of a large proportion of caregivers may account for the additional sources of funds to cater for the direct costs of illness, especially in situations where the cost of treating the illness is more than the monthly income of the patient or household. Many of our respondents got additional funds for their illness, mostly from friends and family (74\% altogether), further confirming the importance of caregivers as important providers of coping strategies. It also points at how many households have been coping with the lack of health insurance which has been recognized as a major intervention in minimizing the effects of chronic illness on the household [23].

It is important to note that the costs of illness vary with the type of disease. As presented in Table 8 , patients with cancer spent significantly more $(\$ 489.07)$ than those with sickle cell disease or asthma, who spent much less. Illnesses such as chronic kidney disease, chronic liver disease, and diabetes resulted in relatively high direct costs. These are illnesses of high severity, which suggests that the more serious and longer-term the illness is, the more burden it places on the family. As Russell [8] has shown, it is likely that households who have to deal with huge costs of managing a disease will struggle or fail to cope with the costs, becoming impoverished or even failing to survive as a social unit. This has been depicted in Table 1 , in which about $46 \%$ of the households earned less than the mean direct cost of treating chronic illness (\$137.72) in this study. For these families to cope, they have to depend on the social resources at their disposal. This is in line with several other studies that have revealed the importance of social resources for households faced with illness costs beyond their budgets [24-26].

Considering the findings obtained and presented herein, it is clear that one patient's chronic illness can be catastrophic on his/her household in terms of the economic implications. Unfortunately, formal health insurance is lacking for many Nigerian households, making them bear the full brunt of these catastrophic effects. Although many of these households have devised other coping strategies, including borrowing from friends or family and selling of vital assets, the effects of managing the patient's chronic illness make them 
lose vital productivity and income, and further pushes them into poverty. These huge economic effects that households bear have significant implications for health policy in Nigeria and other LMICs. Using the example of Thailand and many other countries that have successfully improved the coverage of health insurance, the economic implications of chronic illnesses on households can be significantly minimized with increased coverage of insurance-based financing systems. There is also the need to improve access to effective and specialized health care services that are responsive to the needs of people who have chronic illnesses.

In addition, the findings of this study highlight the importance of health promotion and disease prevention to reduce both the direct and indirect costs of illness to households as well as reduce the cost of running national health services [27-28]. Strength lies in the use of established cost-of-illness methods for estimating economic implications of diseases. However, the major limitations encountered includes difficulty in assessing the monetary value of labor losses due to ill health over a long period of time due to inflation, difficulty in estimating the actual household monthly income (especially for non-salary earners who are not in paid employment), and the exploratory nature of the study that relied on selfreported income and expenditure with the possibility of recall biases. Hence, there is the need for further research on the household costs of illness, household responses, their implications for poverty eradication in LMICs, and how these impacts can be alleviated considering the effects of economic variables.

\section{Conclusions}

There is a need to realize how devastating the economic effects of chronic illnesses are on the families of patients who suffer these illnesses, particularly in Nigeria, as well as other LMICs. It is evident that most families do not have formal support, having to manage the high and catastrophic cost burdens that chronic illnesses place on them. The lack of effective coping strategies also points at the need for policymakers to improve access to specialized care and increase coverage of formal health insurance so as to ameliorate the significant economic impacts that chronic illnesses have on entire households.

\section{Appendices}




\section{Cureus}

\section{SURVEY QUESTIONNAIRE}

A SURVEY TO ASSESS THE ECONOMIC IMPACTS OF CHRONIC ILLNESSES ON HOUSEHOLDS IN SELECTED HEALTHCARE FACILITIES IN IFE CENTRAL LOCAL GOVERNMENT

SN:

This questionnaire is an important part of the research which aims to evaluate the effects of chronic diseases. Your participation in this survey is crucial in order to be able to determine the economic impact of chronic diseases on households. You have been randomly chosen. The data collected for this survey is strictly confidential and the information collected will be used for statistical purposes only; all information will remain anonymous. Kindly provide accurate information.

Please circle answers as appropriate. Thanks in advance for your anticipated cooperation.
A. SOCIO-DEMOGRAPHIC DATA
1. Age (in years):
2. Sex: $1=$ Male $2=$ Female
3. Marital status: $1=$ Single $\quad 2=$ Married $3=$ Separated or Divorced $\quad 4=$ Widowed
4. Employment status: 1=Employed 2=Unemployed $3=$ Not active
5. Occupational description
6. Highest level of education: $1=$ Primary $2=$ Secondary $3=$ Tertiary $4=$ No education
7. Spouse's Occupation
8. Spouse's highest level of education: $1=$ Primary $2=$ Secondary $3=$ Tertiary $4=$ No education
9. Religion: $1=$ Christian $\quad 2=$ Islam $\quad 3=$ Others
10. Nationality:
11. Ethnicity (if Nigerian): $\quad 1=$ Hausa $\quad 2=$ Igbo $\quad 3=$ Yoruba

FIGURE 1: Survey questionnaire - Page 1 


\section{Cureus}

\section{B. HEALTH STATUS}

1. Self-reported health status: $1=$ Excellent $2=$ Very good $3=$ Good $\quad 4=$ Fair $\quad 5=$ Poor

2. Do you have a longstanding disease? $\quad 1=\mathrm{Yes} \quad 2=\mathrm{No}$

3. Do you have a non- longstanding disease? $\quad 1=$ Yes $2=$ No

4. Have you been told you have and been on treatment by the doctor that you have any of the following longstanding diseases for at least 6 months?
a. Hypertension or high blood pressure $1=\mathrm{Yes} \quad 2=\mathrm{No}$
b. Diabetes or sugar problem $1=\mathrm{Yes} 2=\mathrm{No}$
c. Sickle cell disease $\quad 1=$ Yes $2=$ No
d. Asthma $1=$ Yes $2=$ No
e. Anemia $1=$ Yes $2=\mathrm{No}$
f. Any form of cancer $\quad 1=$ Yes $2=$ No
g. Bone or joint problem $\quad 1=$ Yes $2=$ No
h. Chronic kidney disease $1=$ Yes $2=$ No
i. Chronic liver disease $\quad 1=$ Yes $2=$ No
j. Heart disease $\quad 1=$ Yes $2=$ No
Others (Pls specify):

5. Risk factors:
a. Do you think you are overweight? $1=$ Yes $2=$ No
b. Do you engage in physical activities? $\quad 1=$ Yes $2=$ No
c. Do you consume much of fruits and vegetables? 1=Yes $2=$ No
d. Do you consume alcohol? $\quad 1=$ Yes $2=$ No
e. Do you consume tobacco? $\quad 1=$ Yes $2=\mathrm{No}$
f. Do you exercise frequently? $\quad 1=$ Yes $2=\mathrm{No}$
g. Do you have a raised blood pressure? $\quad 1=$ Yes $2=$ No

\section{TREATMENT BEHAVIOR}

1. Did you seek treatment for your condition immediately you felt unwell? $1=$ Yes $2=\mathrm{No}$

2. Where did you first seek for treatment?

1=Pastor $\quad 2=$ Family members $\quad 3=$ Chemist $\quad 4=$ Traditional healer $\quad 5=$ Healthcare facility

3. For how long have you been receiving treatment for your medical condition?

4. Have you missed any of your medications over the last 30 days? $\quad 1=$ Yes $2=$ No

5. Do you receive other forms of alternative treatment like herbal remedies? $1=\mathrm{Yes} \quad 2=\mathrm{No}$

6. Have you ever treated yourself without due consultation with your physician? $1=$ Yes $2=\mathrm{No}$

FIGURE 2: Survey questionnaire - Page 2 


\section{Cureus}

D. ECONOMIC STATUS - Direct and Indirect Costs of Chronic Illness to Households 1. Do you work currently? $1=$ Yes $2=$ No

\begin{tabular}{|c|c|c|c|}
\hline & & & NAIRA/MONTH \\
\hline 2. Household income before the illness ( & ra per month & & \\
\hline 3. Household income since the illness st & 1 (Naira per $\mathrm{r}$ & nth) & \\
\hline 4. Household monthly expenditure (all h & ehold expens & monthly?): & \\
\hline $\begin{array}{l}\text { 5. Household monthly health expenditur } \\
\text { members of your household/month) }\end{array}$ & 1 medical ex & nses for all & \\
\hline $\begin{array}{l}\text { 6. For yourself only, how much do you s } \\
\text { standing illness monthly? }\end{array}$ & d on the treat & ent of your long & \\
\hline $\begin{array}{l}\text { 7. Estimate how much you spend on the } \\
\text { long standing chronic illness every mont }\end{array}$ & owing activit & relating to the tre & tment of your \\
\hline - Drugs & & & \\
\hline - Investigations & & & \\
\hline - Admission & & & \\
\hline - All other forms of treatment (trans & on, operation & hysiotherapy etc) & \\
\hline - Transportation to hospital & & & \\
\hline $\begin{array}{l}\text { 8. Household monthly non-health expen } \\
\text { other things monthly?) }\end{array}$ & re (How muc & lo you spend on & \\
\hline 9. Do you have unsatisfied basic needs? & a. Food & $1=$ Yes $\quad 2=\mathrm{No}$ & \\
\hline & b. Shelter & $1=$ Yes $2=\mathrm{No}$ & \\
\hline & c. Clothing & $1=$ Yes $\quad 2=\mathrm{No}$ & \\
\hline
\end{tabular}

If NO to the above, pls specify

d. The household has no problem with payment of children school fees $1=$ Yes $2=$ No

e. The household has no problem with payment for treatment of any household member $1=$ Yes $2=\mathrm{No}$

10. Total size of the household

11. Number of children (below 18 years) in the household

12. Number of people 65 years or above in the household

13. Number of days out of job due to your longstanding illness in the last 30 days:

14. Number of days carer has been out of job due to patient's longstanding illness in the last 30 days:

FIGURE 3: Survey questionnaire - Page 3 


\section{Cureus}

\section{E.AFFORDABILITY OF HEALTHCARE}

1. Are you able to pay for all your longstanding illness medications? 1=Yes 2=No

2. Are you able to pay for all your longstanding illness investigations? 1=Yes $2=\mathrm{No}$

3. Are you able to pay for admission when necessary for the treatment of your long standing illness? $1=$ Yes $2=$ No

4. Are there some treatment options you have been offered but you are not able to afford? $1=$ Yes $2=$ No

If yes, which one? $1=$ Surgery $2=$ Physiotherapy $3=$ Radiotherapy

5. Do you come to clinic regularly? $1=$ Yes $2=\mathrm{No}$

If No, why? 1 =Lack of money $2=$ Because you forgot 3 =Industrial action Others (please specify):

6. What guides your choice of treatment? 1=Money 2=Doctor's decision 3=Family's decision

\section{F. AFFORDABILITY OF OTHER THINGS}

1. Have you been having difficulty purchasing some basic things like foodstuffs, house rent, clothing, since the illness started? $1=$ Yes $2=$ No

2. Do you think that maintaining your normal lifestyle has become difficult since the illness started?

$1=$ Yes $2=$ No

3. Have you ever had to cut back on some things that you buy normally before? $1=$ Yes $2=$ No

4. Have you ever had to reduce your participation in some social activities (e.g. partying, clubbing) you do before? 1=Yes 2=No

5. Have you ever had to give up leisure activities, hobbies, or other associated expenditures?

$1=$ Yes $2=$ No

\section{G. COPING OR MANAGING STRATEGIES}

1. What are the things you have to forgo in order to have treatment of your longstanding illness?

FIGURE 4: Survey questionnaire - Page 4 
2. Where do you secure money for the treatment of your long standing illness?

$\begin{array}{lll}\text { a. Contributions (gifts/entitlement) from relatives } & 1=\text { Yes } & 2=\mathrm{No} \\ \text { b. } \text { Contributions (gifts/entitlement) from friends } & 1=\mathrm{Yes} & 2=\mathrm{No} \\ \text { c. } \text { Contributions (gifts/entitlement) from employer } & 1=\mathrm{Yes} & 2=\mathrm{No} \\ \text { d. } \text { Contributions (gifts/entitlement) from insurance } & 1=\mathrm{Yes} & 2=\mathrm{No} \\ \text { e. } \text { Self or household from income } & 1=\mathrm{Yes} & 2=\mathrm{No} \\ \text { f. Self or household from sale of property/investments } & 1=\mathrm{Yes} & 2=\mathrm{No} \\ \text { g. Self from a loan from any source } & 1=\mathrm{Yes} & 2=\mathrm{No}\end{array}$

3. Have you ever had to borrow money for any aspect of your treatment at any time? $\quad 1=$ Yes $2=\mathrm{No}$

4. Where did you source for the money? 1=Bank $2=$ Cooperative society $3=$ Church $4=$ Friends $5=$ Family

5. Have you ever had to sell any of your assets to get money for treatment? 1=Yes 2=No

6. Are you on any form of health insurance? $1=$ Yes $2=$ No

7. Has the health insurance reduced the impact of the illness on the family? 1=Yes 2=No

8. Are you on pensions? $1=$ Yes $2=\mathrm{No}$

9. Has the pension reduced the impact of the illness on the family? $1=$ Yes $2=$ No

\section{H. CARER DATA}

1. Do you have anybody caring for you at the moment? $1=$ Yes $2=$ No

2. If YES, what is your carer's relationship to you? $\square$ Father $\square$ Brother $\square$ Mother

$\square$ Sister $\quad \square$ Wife $\quad \square$ Child $\quad \square$ Husband $\square$ Friend $\square$-in law

Others (please specify)

3. Has the carer ever had to leave what he/she was doing before to try and make some money for the family? $1=$ Yes $2=$ No

THANK YOU FOR YOUR TIME...

FIGURE 5: Survey questionnaire - Page 5

\section{Additional Information \\ Disclosures}

Human subjects: Consent was obtained by all participants in this study. Obafemi Awolowo University Teaching Hospitals Complex (OAUTHC) Ethics and Research Committee issued approval. Animal subjects: All authors have confirmed that this study did not involve animal subjects or tissue. Conflicts of interest: In compliance with the ICMJE uniform disclosure form, all authors declare the following: Payment/services info: All authors have declared that no financial support was received from any organization for the submitted work. Financial relationships: All authors have declared that they have no financial relationships at present or within the previous three years with any organizations that might have an interest in the submitted work. Other relationships: All authors have declared that there are no other relationships or activities that could appear to have influenced the submitted work.

\section{References}

1. World Health Organization: Global Status Report on Noncommunicable Diseases 2010. World Health Organization. WHO Press, Geneva, Switzerland; 2011. 9-28.

2. Wang H, Naghavi M, Allen C, Barber RM, Bhutta ZA, Carter A, et al: Global, regional, and national life expectancy, all-cause mortality, and cause-specific mortality for 249 causes of death, 1980-2015: a systematic analysis for the Global Burden of Disease Study 2015. Lancet. 2016, 388:1459-1544. 10.1016/S0140-6736(16)31012-1 
3. World Health Organization: Preventing chronic diseases: a vital investment. World Health Organization, Geneva, Switzerland; 2005.

4. Russell S: Illuminating cases: Understanding the economic burden of illness through case study household research. Health Policy Plan. 2005, 20:277-289. 10.1093/heapol/czi035

5. Suhrcke M, Nugent RA, Stuckler D, Rocco L: Chronic disease: An economic perspective. Oxford Health Alliance, London; 2006.

6. Mohd Dom T, Ayob R, Abd Muttalib K, Aljunid SM: National economic burden associated with management of periodontitis in Malaysia. Int J Den. 2016, 2016:1891074. 10.1155/2016/1891074

7. Russell S: Ability to pay for health care: concepts and evidence. Health Policy Plan. 1996, 11:219-237. 10.1093/heapol/11.3.219

8. Russell S: The economic burden of illness for households in developing countries: A review of studies focusing on malaria, tuberculosis, and human immunodeficiency virus/acquired immunodeficiency syndrome. Am J Trop Med Hyg. 2004, 71:147-155.

9. Sturm R: The effects of obesity, smoking, and drinking on medical problems and costs . Health Aff (Millwood). 2002, 21:245-253. 10.1377/hlthaff.21.2.245

10. Jeon Y, Essue B, Jan S, Wells R, Whitworth JA: Economic hardship associated with managing chronic illness: a qualitative inquiry. BMC Health Serv Res. 2009, 9:182. 10.1186/1472-6963-9-182

11. Gordon L, Scuffham P, Hayes S, Newman BM: Exploring the economic impact of breast cancers during the 18 months following diagnosis. Psychooncology. 2007, 16:1130-1139. 10.1002/pon.1182

12. Okoronkwo IL, Ekpemiro JN, Okwor EU, Okpala PU, Adeyemo FO.: Economic burden and catastrophic cost among people living with type 2 diabetes mellitus attending a tertiary health institution in south-east zone, Nigeria. BMC Res Notes. 2015, 8:527. 10.1186/s13104-015-1489-X

13. Wingfield T, Boccia D, Tovar M, Gavino A, Zevallos K, Montoya R, et al: Defining catastrophic costs and comparing their importance for adverse tuberculosis outcome with multi-drug resistance: a prospective cohort study, Peru. PLoS Med. 2014, 11:1-17. 10.1371/journal.pmed.1001675

14. Berki SE: A look at catastrophic medical expenses and the poor . Health Aff. 1986, 5:138-145. 10.1377/hlthaff.5.4.138

15. Onwujekwe O, Chima R, Okonkwo P: Economic burden of malaria illness on households versus that of all other illness episodes: a study in five malaria holo-endemic Nigerian communities. Health Policy. 2000, 54:143-159. 10.1016/S0168-8510(00)00105-6

16. Xu K, Evans DB, Kawabata K, Zeramdini R, Klavus J, Murray CJ: Household catastrophic health expenditure: A multi-country analysis. Lancet. 2003, 362:111-117. 10.1016/S0140-6736(03)13861-5

17. Blankart C, Koch T, Linder R, Verheyen F, Schreyögg J, Stargardt T: Cost of illness and economic burden of chronic lymphocytic leukemia. Orphanet J Rare Dis. 2013, 8:32. 10.1186/1750-1172-8-32

18. Lyman G, Berndt ER, Kallich JD, Erder MH, Crown WH, Long SR, et al: The economic burden of anemia in cancer patients receiving chemotherapy. Value Health. 2005, 8:149-156. 10.1111/j.1524-4733.2005.03089.x

19. Suhrcke M, Rocco L, McKee M, Mazzuco S, Urban D, Steinherr A: Economic consequences of noncommunicable diseases and injuries in the Russian federation. World Health Organization, Regional Office for Europe, Copenhagen, Denmark; 2007.

20. Nigeria GDP - per capita (PPP) . (2017). Accessed: July 12, 2017: http://www.indexmundi.com/nigeria/gdp_per_capita_(ppp).html.

21. Kamolratanakul P, Sawert H, Kongsin S, et al.: Economic impact of tuberculosis at the household level . Int J Tuberc Lung Dis. 1999, 3:596-602.

22. Supakankunti S: Future prospects of voluntary health insurance in Thailand . Health Policy Plan. 2000, 15:85-94. 10.1093/heapol/15.1.85

23. Alam K, Mahal A: Economic impacts of health shocks on households in low and middle income countries: a review of the literature. Global Health. 2014, 10:21. 10.1186/1744-8603-10-21

24. Hoque ME, Dasgupta SK, Naznin E, Al Mamun A: Household coping strategies for delivery and related healthcare cost: findings from rural Bangladesh. Trop Med Int Health. 2015, 20:1368-1375. 10.1111/tmi.12546

25. Binnendijk E, Koren R, Dror DM: Hardship financing of healthcare among rural poor in Orissa, India . BMC Health Serv Res. 2012, 12:1-13. 10.1186/1472-6963-12-23

26. Leive A, Xu K: Coping with out-of-pocket health payments: empirical evidence from 15 African countries . Bull World Health Organ. 2008, 86:849-856. 10.2471/BLT.07.049403

27. Improving health outcomes of the poor. (2002). Accessed: February 15, 2017: http://apps.who.int/iris/bitstream/10665/42488/1/9241590130.pdf.

28. Lekhan V, Rudiy V, Richardson E: Ukraine: health system review. Health Syst Transit. 2010, 12:1-183. 